\title{
Variational Finite Element Approach to Study Radial Heat Distribution Problem in Human Limbs
}

\author{
Sonia Shivhare \\ Department of Mathematics, Amity University Madhya Pradesh, India
}

\begin{abstract}
This paper is based on bio heat transfer equation and demonstrates its application in solving one dimensional physiological heat distribution problems pertaining to limbs. The biological properties are assumed to vary along the radial direction. The dermal region is made up of three layers, namely epidermis, dermis, and subcutaneous tissues. The model incorporates significant variations of physical and physiological parameters like blood mass flow rate, rate of metabolic heat generation, and thermal conductivity in each layer. Numerical results have been obtained for various cases of practical interest.
\end{abstract}

Keywords: Rate of metabolism 1, blood mass flow rate 2, thermal conductivity 3, heat generation 4, finite element method 5.

\section{Introduction}

The one dimensional models for heat distribution in limbs have wide scope as the core temperature of the human limbs varies extensively at lower atmospheric temperatures. For falling atmospheric temperature, the body core shrinks rapidly and isotherm shells in the limb change their respective position gradually. This may be due to the fact that the arterial blood has cooled down while flowing towards the extremities. Also the two opposite side of inner core of a human limb may be at different temperature. This may be because one side of the limb contains major blood vessels (arteries) with blood coming from main trunk at body core temperature and the outer side of the limb contains veins with blood returning from the extremities at lower temperature.

Perl[1] combined differential forms of Fick's perfusion principle with heat conduction and matter diffusion equations and metabolic term to obtain equation. He used equation to solve its simple cases by taking all parameters as constant throughout the region. Perl and Hirsch[2] used this equation to test the transient response for measuring local tissue blood flow on dog and rabbit kidney. Trezek and Cooper[3] computed thermal conductivity of tissue by taking all parameters as constant. Cooper and Trezek [4] obtain solution of equation in SST region by taking all parameters as constant. Patterson[5] made experimental attempts, to determine temperature profiles in skin and subcutaneous region.

This paper employs a variational finite element approach to study the temperature distribution in a normal cross-sectional region of a limb. Due to unsymmetric situations of large blood vessels passing through the core of the limb the inter-face has angular variation. The peripheral part of limb is directly exposed to atmosphere..Different types of variations of parameters have been considered for different natural subregions such as stratum corneum, stratum germinitivum, dermis and underlying tissue (Montagana [6], Jarrett [7]and Gray [8]). Finite element formulation provides necessary flexibility in taking care of different behavior of distinctly different subregions.

\section{Material and Methods}

The heat flow in SST region is given by the following partial differential equation

$$
\operatorname{div}(K \operatorname{grad} T)+m_{b} C_{b}\left(T_{b}-T\right)+S=\rho \bar{c} \frac{\partial T}{\partial t}
$$

Where $\mathrm{T}$ and $\mathrm{T}_{\mathrm{b}}$ are Temperature and Body core temperature ,S is Rate of metabolic heat generation , $\mathrm{m}_{\mathrm{b}}$ is Blood mass flow rate in the tissue,$\rho$ is density of the tissue. $\mathrm{C}_{\mathrm{b}}=$ Specific heat of blood, $\mathrm{K}$ is thermal conductivity of the tissue. Above equation has been modified and extensivelyused by Saxena [9], Saxena and Arya [10], Saxena and Bindra [11,12] in the thermal study of human skin andsubcutaneous tissue.

In this, skin and underlying tissues of cylindrical regions such as limbs of a human are divided into four annualar layers. They can be considered as multi layered regions. Each layer has different physical and physiological properties. The outer body surface is exposed to the environment and heat loss from the body surface takes place due to conduction, convection, radiation and evaporation. Here we employ for a human limb with circular symmetry. The properties and temperature distribution are assumed to be uniform along $\theta$ and $\mathrm{Z}$ directions. Thus the equation reduces in one dimensional unsteady state case for each layer to the following cylindrical from. 


$$
\frac{1 d}{r d r}\left(k^{(i)} r \frac{d T_{j}}{d r}\right)+M_{i}\left(T_{b}-T_{i}\right)+S_{i}=\rho \bar{C} \frac{\partial T}{\partial t}, \quad i=1 \text { to } 4
$$

Where $\mathrm{K}^{(\mathrm{i})}, \mathrm{M}_{\mathrm{i}}, \mathrm{S}_{\mathrm{i}}$ and $\mathrm{T}_{\mathrm{i}}$ denote the values of $\mathrm{K}, \mathrm{M}, \mathrm{S}$ and $\mathrm{T}$ in $\mathrm{i}$ the sub-region.

\section{Boundary and Interface Conditions:}

In view of continuity of temperature and temperature gradient in various sublayers, the following boundary and interface conditions can be formulated

(i) $\quad \mathrm{T}^{(1)}=\mathrm{T}^{(2)}$

$K_{1} \frac{d T^{(1)}}{d r}=K_{2} \frac{d T^{(2)}}{d r}$

$$
\text { at } \quad \mathrm{r}=\mathrm{a}_{1}
$$

(iii) $\quad T^{(2)}=T^{(3)}$

$$
\text { at } \quad \mathrm{r}=\mathrm{a}_{1}
$$

(iv)

$$
K_{2} \frac{d T^{(2)}}{d r}=K_{3} \frac{d T^{(3)}}{d r}
$$

$$
\text { at } \quad \mathrm{r}=\mathrm{a}_{2}
$$

(v) $\quad \mathrm{T}^{(3)}=\mathrm{T}^{(4)}$

$$
K_{3} \frac{d T^{(3)}}{d r}=K_{4} \frac{d T^{(4)}}{d r}
$$$$
\text { at } \quad \mathrm{r}=\mathrm{a}_{2}
$$$$
\text { at } \quad \mathrm{r}=\mathrm{a}_{3}
$$$$
\text { at } \quad \mathrm{r}=\mathrm{a}_{3}
$$

It is assumed that at the outermost layer $\left(\mathrm{r}=\mathrm{a}_{0}\right)$ the heat is lost to the environment by conduction, convection, radiation and evaporation. Therefore at this layer we take

$$
K_{1} \frac{d T}{d r}=-h\left(T-T_{A}\right)+L E
$$

Where $\mathrm{h}$ is coefficient of convection, $\mathrm{L}$ is latent heat of evaporation and $\mathrm{E}$ is the Rate of sweat evaporation $\mathrm{T}_{\mathrm{A}}$ is the atmospheric temperature. At the innermost layer the temperature will be same as that of the body core. Hence the boundary conditions will be $\mathrm{T}_{4}=\mathrm{T}_{\mathrm{b}}$ at $\mathrm{r}=\mathrm{a}_{4}$

\section{Solution of the Problem:}

The variational form is defined in the region as $I_{1}, I_{2}, I_{3}$ and $I_{4}$ respectively for stratumcorneum, stratumgermativum, dermis and subdermal parts. Assigning the values to $T$ as $T_{i}(i=0,1,2,3,4)$ called as nodal values. The distance between the nodal values is given by $a_{i}(I=0,1,2,3,4)$ from the outermost layer of epidermis to innermost layer of subdermal layer.Let $\mathrm{T}^{(\mathrm{i})}(\mathrm{i}=1,2,3,4)$ denote the linear values of $\mathrm{T}(\mathrm{r})$ for $a_{i}<r<a_{i-1}$

Now, applying the shape function to approximate the solution of the problem.

$$
T^{(i)} \approx A_{i}+B_{i} r \quad \text { for } \quad a_{i}<r<a_{i-1}
$$

Where,

$$
A_{i}=\frac{T_{i}-T_{i-1}}{a_{i}-a_{i-1}}, \quad B_{i}=\frac{a_{i-1} T_{i}-a_{i} T_{i-1}}{a_{i-1}-a_{i}} \text { for } \quad i=2,3,4
$$

Thus the equation in one dimensional unsteady state case for each layer to the following cylindrical form

$$
\frac{1}{r} \frac{d}{d r}\left(K r \frac{d T}{d r}\right)+M\left(T_{b}-T\right)+S=\rho \bar{C} \frac{\partial T}{\partial t},
$$

After camparing with Euler's Lagrange's equation, we get the varitional forms

$$
\begin{gathered}
I=\frac{1}{2} \int_{a_{i}}^{a_{i}-1}\left[K_{1} r\left(\frac{\partial T^{i}}{\partial t}\right)^{2}+r m_{b} C_{b}\left(T^{i}-T_{b}\right)^{2}-2 s^{(i)} r T^{(i)}+\rho \bar{c} r \frac{\partial T(i)^{2}}{\partial T}\right] d r \\
+\frac{1}{2} h\left(T_{(1)}^{(c)}-T_{a}\right)^{2}+\operatorname{LET}_{(i)}
\end{gathered}
$$

We have,

Clearly,

$$
\mathrm{I}=\mathrm{I}_{1}+\mathrm{I}_{2}+\mathrm{I}_{3}+\mathrm{I}_{4}
$$

$\mathrm{I}=\mathrm{f}\left(\mathrm{T}_{0}, \mathrm{~T}_{1}, \mathrm{~T}_{2}, \mathrm{~T}_{3}, \mathrm{~T}_{4}\right)$ 
Now minimizing I with respect to parameters $\mathrm{T}_{0}, \mathrm{~T}_{1}, \mathrm{~T}_{2}, \mathrm{~T}_{3}$, therefore

$\frac{\partial I}{\partial T_{0}}+\frac{\partial I}{\partial T_{1}}+\frac{\partial I}{\partial T_{2}}+\frac{\partial I}{\partial T_{3}}=0$

Finally taking La-place transform, we get four non homogenous simultaneous equations as

$\mathrm{x}_{1} \mathrm{~T}_{0}+\mathrm{y}_{1} \mathrm{~T}_{1}=\mathrm{n}_{1}$

$\mathrm{x}_{2} \mathrm{~T}_{0}+\mathrm{y}_{2} \mathrm{~T}_{1}+\mathrm{z}_{2} \mathrm{~T}_{2}=\mathrm{n}_{2}=\mathrm{n}_{2}$

$\mathrm{y}_{3} \mathrm{~T}_{1}+\mathrm{z}_{3} \mathrm{~T}_{2}+\mathrm{w}_{3} \mathrm{~T}_{3}=\mathrm{n}_{3}$

$\mathrm{z}_{4} \mathrm{~T}_{2}+\mathrm{w}_{4} \mathrm{~T}_{4}=\mathrm{n}_{4}$

solving for $\bar{T}_{0}, \bar{T}_{1}, \bar{T}_{2}, \bar{T}_{3}$ by using matrix method, we get the values of $\overline{T_{0}}, \overline{T_{1}}, \overline{T_{2}}, \overline{T_{3}}$ in the form of polynomials

$\left[\begin{array}{llll|l}x_{1} & y_{1} & 0 & 0 & \eta_{1} \\ x_{2} & y_{2} & z_{2} & 0 & \eta_{2} \\ 0 & y_{3} & z_{3} & \omega_{3} & \eta_{3} \\ 0 & 0 & z_{4} & \omega_{4} & \eta_{4}\end{array}\right]$

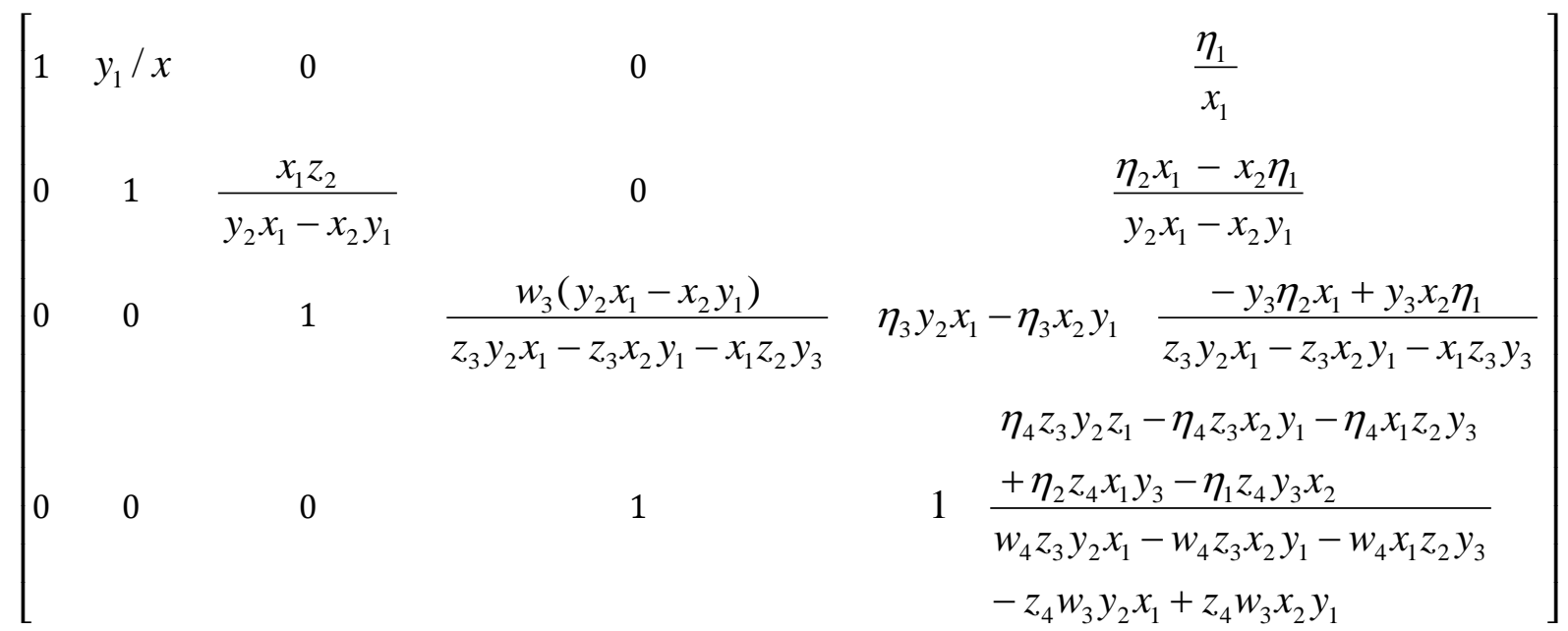

$$
\begin{aligned}
& \overline{T_{1}}=\frac{X_{i}(p)}{Y_{1}(p)}
\end{aligned}
$$

Where $\mathrm{x}_{i}(\mathrm{p})$ is a polynomial of degree less than $\mathrm{n}$ that of $\mathrm{Y}_{j}(\mathrm{P})$ i.e., $(\mathrm{n}-1)$

The value of nodal temperature $\mathrm{T}_{0} \mathrm{~T}_{1} \mathrm{~T}_{2} \mathrm{~T}_{3}$, can be obtained by taking the inverse La-place transform $\mathrm{T}_{1}=\sum_{n=1}^{N} \frac{X_{1}\left(p_{N}\right)}{y_{1}\left(p_{N}\right)} \mathbf{e}^{p n t}$

Therefore, we can see that nodal values are dependent on time.

\section{Tables}

The numerical result have been obtained with the help of following values - 


\begin{tabular}{|c|c|c|}
\hline $\begin{array}{l}\text { Thermal Conductivity } \\
\left(\mathrm{cal} / \mathrm{cm} \mathrm{min}{ }^{\circ} \mathrm{C}\right)\end{array}$ & $\begin{array}{l}\text { Heat Transfer Coefficient } \mathrm{h} \\
\left(\mathrm{cal} / \mathrm{cm}^{2} \min { }^{\circ} \mathrm{C}\right)\end{array}$ & $\begin{array}{l}\text { Specific Heat of Tissues c (cal/gm } \\
\left.{ }^{\circ} \mathrm{C}\right)\end{array}$ \\
\hline $\mathrm{K}_{1}=0.060, \mathrm{~K}_{2}=0.045, \mathrm{~K}_{3}=0.030$ & 0.009 & 0.830 \\
\hline $\begin{array}{l}\text { Blood Density of Tissues } \\
\left(\mathrm{gm} / \mathrm{cm}^{3}\right)\end{array}$ & $\begin{array}{l}\text { Latent Heat } \\
\text { (cal/gm) }\end{array}$ & $\begin{array}{ll}\text { Body } & \text { Core } \\
\mathrm{T}_{\mathrm{b}}\left({ }^{\circ} \mathrm{C}\right) & \\
\end{array}$ \\
\hline 1.090 & 579.0 & 37 \\
\hline
\end{tabular}

The numerical result have been computed for three case of atmospheric temperatures $\mathrm{T}=15{ }^{\circ} \mathrm{C}, 23^{\circ} \mathrm{C}$ and $33^{\circ} \mathrm{C}$. The following sets of numerical values have been taken and graphical representation obtained for temperature distribution in SST region. The three different set of values for thickness of layers in SST region are taken for $\mathrm{a}_{0}, \mathrm{a}_{1}, \mathrm{a}_{2}, \mathrm{a}_{3}$ and $\mathrm{a}_{4}$.

\begin{tabular}{|l|l|l|l|l|l|}
\hline Thickness of Skin & $\mathrm{a}_{0}$ & $\mathrm{a}_{1}$ & $\mathrm{a}_{2}$ & $\mathrm{a}_{3}$ & $\mathrm{a}_{4}$ \\
\hline Set I & 8 & 7.5 & 7 & 6 & 5.5 \\
\hline Set II & 7.5 & 7 & 6 & 5 & 4.5 \\
\hline Set III & 7 & 6 & 6.5 & 5 & 5.5 \\
\hline
\end{tabular}

\section{Conclusion}

Different $\mathrm{T}^{(\mathrm{i})}(\mathrm{i}=0,1,2,3)$ vs time $\mathrm{t}$ for different thickness of skin and different values of atmospheric temperatures have been calculated On comparing the nodal temperature on outer surface and in each sub region, it is observed that these nodal temperatures vary considerably with the change in atmospheric temperatures and rate of sweat evaporation.

Obviously sharpness of gradient is more marked in the epidermal sub- layer which is directly exposed to environment. Moreover blood flatter in the dermal and sub dermal sub layers.

\section{Reference}

[1]. W.Perl Heat and matter distribution in body tissue and determination of tissue blood flow by local clearance methods" journal of theoretical biology 2(3),1962,201-235

[2]. Perl,W. and Hirsch, R.L. ,Local blood flow in kidney tissue by heat clearance method, J. Theoret.Biol. 10(2), 1966, 251-280

[3]. Cooper, T.E. and Trezek, G.J.,A Probe technique for determining the thermal conductivity of tissues, J. Heat transfer, ASME 94 , 133-140,1972,a.

[4]. Cooper, J.E. and Trezek, G.T.,on the freezing of tissues, J. Heat transfer, ASME, 94,251-253,1972,b.

[5]. Patterson, A.M., Measurement of temperature profiles in human Skin, S.Afr J. Sci, 72, 78-79,1976

[6]. MONTAGNA, W. The Structure and Function of Skin.., Academic Press (1962).

[7]. JARRETr, A. The Physiology and Pathophysiology of Skin, Academic Press (1973).

[8]. GRAY, H. Text Book of Gray's Anatomy, Longmans Press (1973)

[9]. SAXENA, V. P. Temperature Distribution in Human Skin and Subdermal Tissues, ,1, Theo. Biol,102 (1983), $277-286$.

[10]. SAXENA, V. P. and ARYA, D. Exact Solution of the Temperature Distribution Problem in Epidermis and Dermis Regions ofHuman Body, Proc. VNM, Medical and Biological Engineering, Sweden (1981), 364-366.

[11]. SAXENA, V. P. and BINDRA. J. S. Steady State Temperature Distribution in Dermal Regions of Human Body with Variable Blood Flow, Perspiration and Self-Controlled Metabolic Heat Generation, J. Pure Appl. Math. 15(1) (1984), 31-42.

[12]. SAXENA, V. P. and BINDRA, J. S. Quadratic Shape Functions in Variational Finite Element Approach to Heat Distribution in Cutaneous and Subcutaneous Tissues, Ind. J. pure Appl. Math..L_8(9) (1987), 846-855. 